\title{
O CONTROLE SOCIAL LOCALIZADO EXERCIDO PELA POLÍCIA COMO PONTO DE PARTIDA PARA A SELETIVIDADE DA CRIMINALIZAÇÃO SECUNDÁRIA
}

\author{
Kenneson Lima Ferreira \\ http://buscatextual.cnpq.br/buscatextual/visualizacv.do?id=K4327069H
}

\begin{abstract}
"A todos aqueles que neste momento habitam um ventre e que nascerão na miséria, morarão nas ruas, terão como teto o tempo, sentirão frio, acostumar-se-ão com o medo, comerão lixo, cheirarão cola, conhecerão o sexo na infância, procriarão na puberdade e, analfabetos, morrerão antes de atingirem a idade adulta. Sua vida já é conhecida, antes de nascerem, filhos órfãos que são da cidade grande. Muitos dos que sobreviverem, seu caminho também não é mistério, pois as portas da prisão os aguardam.

Que a criminologia contribua para a compreensão dos fenômenos sociais sobre os quais se debruça e com isso, quem sabe, algum vetor social permita uma realidade menos dramática e menos infeliz do que a lógica óbvia do determinismo acima descrito"
\end{abstract}

Resumo: O artigo "o controle social localizado exercido pela polícia como ponto de partida para a seletividade da criminalização secundária", faz uma análisesobre as formas de controle social,sobre a criação da figura do criminosoatravés daseleção dos bens protegidos pelo direito penal - criminalização primária-, para, ato contínuo, buscardeslindar, sem o intuito de esgotar a discussão, as funções latentes docontrole social exercido pela polícia no meio urbano, caracterizado por atuações diferenciadas sobre os grupos que são marginalizados.

Palavras-Chaves: Seletividade penal, Controle Social, Polícia, Classes marginalizadas.

\section{The Local Social Control exercised by the Police as a Starting Point to the Selectiveness of Secondary Criminalization}

Abstract: The article "The Local Social Control exercised by the Police as a starting point to the selectiveness of Secondary Criminalization" makes an analysis of the forms of social control and of the creation of the criminal's figure through the selection of assets protected by criminal law - primary criminalization-in order to seek to unravel without the intention of exhausting the discussion, the latent functions of social control exercised by the police in urban areas characterized by different performances of the groups that are marginalized.

Keywords: Criminal Selectivity, Social Control, Police, Marginalized Classes

\section{INTRODUÇÃO}

1 Freitas (2002, p. 6) 


\section{REVISTA ELETRÔNICA DA FACULDADE DE DIREITO DE FRANCA \\ www.revista.direitofranca.br \\ v. 6, n.1, dez/2012, ISSN: 1983-4225}

Decerto, a violência policial é um problema crônico no Brasil. Assim, o presente artigo se propõe a analisar, com uma visão crítica, a atividade policial diferenciada no tratamento de específicos grupos sociais, tendo em vista à incoerência desse comportamento em um Estado Democrático de Direito.

Para tanto, destacaremos o legado autoritário brasileiro, consubstanciado em várias instituições da nossa sociedade que ainda carecem de uma adaptação democrática.

Nosso principal foco será a polícia que devido a uma transformação nas formas de controle social, passou a ser uma das principaisinstituições utilizada para tal fim no meio urbano, em seguida, buscar-se-á demonstrar a criação do estereótipo do delinquente - através da criminalização primária -, para, ao final, frisar a consequente movimentação daquela instituição de controle social para uma atuação localizada sobre os grupos marginalizados.

Buscaremos esclarecer que essa vigilância direcionada é causa de um grande problema, o qual se torna ainda mais grave na medida em que a polícia é detentora de um poder legitimado para a eficácia de sua incumbência - busca do apaziguamento social, manutenção da ordem social e em ultima ratio estabelecer o bem comum -.

Em suma, o caminho do presente trabalho é uma correlação entre o controle social, a marginalização de determinados grupos e a consequente incidência do controle social institucionalizado sobre aqueles que são excluídos.

\section{BRASIL, AUTORITARISMO E CONTROLE SOCIAL}

É cediço que o Estado surgiu e se mantém, por meio de ideologias que buscam sua legitimação, dentre as quais, se destaca aquela cujo objetivo é a busca do bem comum, consubstanciada na possibilidade de convivência social harmônica. Exsurge, para dita função, meios legitimados, conhecidos como instituições de controle ao corpo social.

Nesse diapasão, o controle social exercido pelo Estado se vale desde meios mais ou menos "difusos" e encobertos até meios específicos e explícitos, como é o sistema penal (Polícias, Ministério Público, órgãos da Magistratura, órgãos da Administração Penitenciária) (ZAFFARONI; PIERANGELI, 2004, p. 61).

Assim, para avaliar o controle social em um determinado contexto, não se deve deterse apenas ao sistema penal, mas é necessário analisar outros aspectos que tornam 


\title{
REVISTA ELETRÔNICA DA FACULDADE DE DIREITO DE FRANCA \\ www.revista.direitofranca.br \\ v. 6, n.1, dez/2012, ISSN: 1983-4225
}

complicadíssimo o tecido social, a exemplo da estrutura familiar (autoritária ou não), da educação (a escola, os métodos pedagógicos, o controle ideológico dos textos, a universidade, a liberdade de cátedra etc.). De maneira que caso não se proceda assim, esquecendo, portanto, da pluridimensionalidade do fenômeno do controle, o pesquisador cairá em um simplismo ilusório(ZAFFARONI; PIERANGELI, 2004, p. 61-62).

Posto isso, com o fim de não cair em ilusões, tampouco obter resultados superficiais, far-se-á à análise de duas instituições da nossa sociedade, quais sejam -Família e Escola -, com o objetivo de observarmos a extensão e complexidade do nosso controle social, e, com o resultado, verificarmos se nossa sociedade é mais ou menos autoritária ou mais ou menos democrática, na medida em que essa característica determinará o rigor do controle social.

Nesse sentido, é imprescindível abordarmos o patriarcalismo, vez que foi a estrutura familiar predominante na sociedade brasileira nos tempos coloniais, na qual o pai detinha o poder de gerir os mais variáveis interesses da família, sendo, portanto, o centro das decisões.

Nessa estrutura, o patriarca não admitia ser contrariado, suas ordens e vontades passavam por cima de qualquer obstáculo, inclusive a lei. Como autoridade maior podia decidir de forma arbitraria os destinos de seus subordinados.

Não era incomum que o poder absoluto do patriarca ultrapassasse as relações familiares e de escravidão, alcançando agregados, autoridades religiosas, jurídicas e políticas.

Exercendo um poder sem freios, o pai ignorava ou combatia qualquer interferência externa (HOLANDA, 1995, p. 81).Outrossim, era comum a solução dos conflitos na esfera privada sem nenhuma objeção externa, inclusive com sentenças de morte.

Exemplifica Holanda (1995, p. 82) que,

\begin{abstract}
Nesse ambiente, o pátrio poder é virtualmente ilimitado e poucos freios existem para sua tirania. Não são raros os casos como o de um Bernardo Vieira de Melo, que, suspeitando a nora de adultério, condena-a à morte em conselho de família e manda executar a sentença, sem que a justiça dê um único passo no sentido de impedir o homicídio ou de castigar o culpado, a despeito de toda a publicidade que deu ao fato o próprio criminoso.
\end{abstract}

Nada obstante essa estrutura familiar seja típica do período colonial, ela ainda gera repercussão nos dias atuais, na medida em que na maioria dos lares brasileiros o pai ainda ocupa uma posição central nas tomadas de decisões, o que demonstra a força da nossa herança histórica autoritária. 


\section{REVISTA ELETRÔNICA DA FACULDADE DE DIREITO DE FRANCA \\ www.revista.direitofranca.br \\ v. 6, n.1, dez/2012, ISSN: 1983-4225}

No que tangeao sistema escolar, ele é enraizado no método tradicional, isto é, na relação entre professor e aluno temos aquele como o único detentor do conhecimento vez que "a escola se organiza, pois, como uma agência centrada no professor, o qual transmite, segundo uma gradação lógica, o acervo cultural aosalunos. A estes cabe assimilar os conhecimentos que lhes são transmitidos"(SAVIANI,1996, p. 06).

Nesse método o aluno se resume a um sujeito passivo, receptor e armazenador do "conhecimento" alheio, na medida em que não há oportunidade para questionamentos, tampouco para discordância, máxime porque a divergência é encarada, em regra, como uma afronta ao "conhecimento" do professor.

Logo, nosso ensino ao trazer tais características afasta-se de uma visão educacional democrática e progressista, vez que ensinar não é transferir conhecimento, mais criar oportunidades para a sua construção através do incentivo à curiosidade e as indagações (FREIRE, 1996, p. 21).

Ademais, a maioria das nossas escolas de ensino fundamental e médio ainda adota um livro padrão para todos os alunos, essa atitude traz à tona um rigoroso controle social, pois além de limitar o "conhecimento", torna-o uniforme.

Em outras palavras, temos um conhecimento pronto e não construído (método baseado na pesquisa), advém daí nossa dificuldade na formação de pesquisadores (FREIRE, 1996, p. $35)$.

Desta maneira, em uma sociedade, como a brasileira, cujas raízes demonstram a tendência de que as posições tomadas de forma arbitrária não podem sofrer oposições, e que também através do sistema escolar busca uniformizar os valores vigentes no meio social, é de fácil percepção a presença do autoritarismo (ordens não podem ser contrariadas), o que tem influência direta, junto com outros fatores, na rigidez do nosso controle social.

Além disso, ainda com a finalidade de traçarmos princípios ao presente trabalho, é preciso fazer algumas considerações acerca da diferença do controle social exercido na esfera privada frente ao da esfera pública.

No Brasil, o controle social no meio rural era exercido, em regra, pela esfera privada, isto é, pela família e pelos costumes, todavia, com as mudanças inerentes ao crescimento urbano, tivemos o declínio da eficácia destas instituições de controle frente ao fortalecimento das instituições da esfera pública. 


\title{
REVISTA ELETRÔNICA DA FACULDADE DE DIREITO DE FRANCA \\ www.revista.direitofranca.br \\ v. 6, n.1, dez/2012, ISSN: 1983-4225
}

Assim, a família e os costumes (esfera privada) foram dando lugar a escola e a polícia (esfera pública), vez que são essas as instituições que exercem de forma predominante o controle social no espaço urbano.

Freitas (2002, p. 37) percebe muito bem esse fenômeno quando diz que,

\begin{abstract}
Com tantas e abruptas mudanças, as formas tradicionais de controle social se desvanecem, passando este controle a ser exercido não mais na esfera privada, mas primordialmente na esfera pública. Os costumes perdem força coercitiva, que passa a ser exercida pela lei. O papel da família e da religião cede cada vez mais lugar à escola, pública em sua maioria, instrumento de reprodução da ordem social, e à polícia, instrumento de repressão aos que desafiarem esta ordem.
\end{abstract}

Com efeito, enquanto a escola é o instrumento de reprodução da ordem social vigente, a polícia é o meio de retenção daqueles que se desviarem dos comportamentos estabelecidos por ela.

\section{CRIMINALIZAÇÃO PRIMÁRIA: SELEÇÃO PELO LEGISLADOR DOS BENS RELEVANTES PARA A SOCIEDADE E A CONSEQUENTE FIGURA DO DELINQUENTE}

$\mathrm{O}$ art. $1^{\mathrm{o}}$ da nossa Constituição Federal de 1988 institui de forma expressa a determinação da República Federativa do Brasil como um Estado Democrático de Direito², entretanto, muito longe dos ideais democráticos e republicanos, a história revela que no nosso país $^{3}$, o interesse privado é entrelaçado ao público, e não raro aquele prepondera sobre este.

Essa situação é agravada porque a maioria do povo brasileiro não é colocada em condições reais de decisão, na medida em que desconhece a importância dos princípios e fundamentos democráticos (voto secreto e o sufrágio universal), determinantes para a expressão de seus interesses. Além do que, desconhece a importância da função legislativa.

Desta maneira, por não ser colocado em condição suficiente para expressar seus desejos e necessidades, máxime pela miséria do nosso povo, este não se utiliza da sua soberania para eleger aqueles que deveriam defender seus interesses, abrindo oportunidade para representantes que não têm sensibilidade e compromisso suficiente para decidir em harmonia com a vontade daqueles que elesrepresentam (GUIMARÃES, 2010, p. 107).

\footnotetext{
${ }^{2}$ Art. $1^{\text {o }}$ da CF/1988: A República Federativa do Brasil, formada pela união indissolúvel dos Estados e Municípios e do Distrito Federal, constitui-se em Estado Democrático de Direito (...).

${ }^{3}$ Maiores detalhes em Holanda (1995).
} 


\title{
REVISTA ELETRÔNICA DA FACULDADE DE DIREITO DE FRANCA \\ www.revista.direitofranca.br \\ v. 6, n.1, dez/2012, ISSN: 1983-4225
}

Toda essa situação faz com que a classe dominante, se aproveitando da ignorância do povo, componha o poder legislativo, de sorte a adquirir, por conseguinte, um poder legitimado para elaborar as leis que regulamentarão a sociedade em múltiplas questões.

Em outros termos, o legislativo não trabalha em proveito do povo, buscando o bem comum (coletividade), mas ao contrário, movimenta-se para proteger os interesses de uma classe dominante, os quais são transformados, através de ideologias, em interesses gerais.

Sobre o tema Sabadell (2008, p. 175) afirma que,

\begin{abstract}
Estes grupos apresentam a proteção de seus interesses particulares como uma reação legítima de "toda a sociedade" contra o "mal" encarnado na figura do criminoso. Em outras palavras, os referidos grupos possuem o poder de definição dos comportamentos desviantes e conseguem, também, controlar a aplicação das normas jurídicas. Assim sendo, o direito penal protege os interesses dos mais fortes, que são apresentados, ideologicamente, como interesses gerais.
\end{abstract}

É indiscutível que em uma sociedade plural existam grupos que estão mais próximos das decisões, e que, por isso,utilizam o Estado para o seu sustento. Assim, esse poder de definição, sobretudo no âmbito penal,é imprescindível para que a classe dominante mantenha sua hegemonia na estrutura do poder, uma vez que direciona as instituições de controle social para uma criminalização e neutralização dos comportamentos típicos dos grupos mais afastados (ZAFFARONI E PIERANGELI, 2004, p. 76).

Posto isso, sendo o direito penal o instrumento normativo mais violento para a regulamentação da sociedade, em nosso Estado Democrático de Direito, esse instrumento é limitado por vários princípios que garantem a proteção do cidadão frente ao jus puniendi do Estado, todavia, por oportuno, ressaltaremos apenas o princípio da intervenção mínima, o qual preceitua que o direito penal deverá proteger somente em ultima ratio os interesses mais importantes para a sociedade contra eventuais ataques que os coloquem em perigo. De forma que, a criminalização de uma conduta só poderá ser legitima, se for a única forma possível para a proteção de um determinado bem jurídico, isto é, se outras formas de sansões ou outros meios de controle social forem suficientes para a tutela deste, afasta-se a necessidade de uma atuação penal, vez que pelo princípio da intervenção mínima o direito penal assume um caráter subsidiário (BITENCOURT, 2005, p.32).

Dito de outro modo, nem todas as ações indesejáveis e imorais serão eleitas como fato típico, e, portanto, como consequência, abrirão a possibilidade de uma solução penal, basta lembrarmos dos conflitos resolvidos na esfera civil e trabalhista. Nesse sentido é importante 


\title{
REVISTA ELETRÔNICA DA FACULDADE DE DIREITO DE FRANCA \\ www.revista.direitofranca.br \\ v. 6, n.1, dez/2012, ISSN: 1983-4225
}

destacar que a eleição para a tipificação de uma ou outra conduta é norteada pelos valores vigentes no contexto social à época da escolha.

O certo é que em um Estado Democrático de Direito os interesses selecionados pelos legisladores e consubstanciados na norma penal, devem respeitar a pluralidade da sociedade.

Todavia, em que pese "no Brasil assistirmos ao cumprimento de todas as formalidades democráticas atinentes ao processo eleitoral, como voto secreto e o sufrágio universal" (GUIMARÃES, 2010, p. 118), essas garantias “não impedem às elites oligárquicas de recorrerem aos meios de manipulação - abuso de poder econômico, uso abusivo dos meios de comunicação de massa, entre outros - para obtenção do necessário consenso mínimo que as eleve ao poder" (GUIMARÃES, 2010, p. 118).

Em sendo assim, aqueles que têm o poder para legislar, em regra, são da classe dominante, e, portanto, criam as normas incriminalizadoras partindo dos interesses inerentes a sua classe, estampados em seus valores.

Assim se posiciona Baratta (1999, p. 176),

\begin{abstract}
No que se refere ao direito penal abstrato (isto é, à criminalização primária), (...). O sistema de valores que nele se exprime reflete, predominantemente, o universo moral próprio de uma cultura burguesa-individualista, dando a máxima ênfase à proteção do patrimônio privado e orientando-se, predominantemente, para atingir as formas de desvio típicas dos grupos socialmente mais débeis e marginalizados. Basta pensar na enorme incidência de delitos contra o patrimônio (...) e a espécie de conexão que eles determinam com o mecanismo das agravantes e das atenuantes (é difícil, como se sabe, que se realize um furto não "agravado").
\end{abstract}

No ordenamento penal brasileiro é claramente perceptível à ênfase legislativa na proteção do patrimônio, ora, basta lembrarmos que se, por exemplo, um determinado sujeito subtrair uma coisa alheia móvel, para si ou para outrem, mediante grave ameaça ou violência a pessoa, ou depois de havê-la, por qualquer meio, reduzido à impossibilidade de resistência, comete o crime de roubo, tipificado no art. $157^{4}$ do Código Penal Brasileiro, já se realizar a mesma ação sem a violência, porém com destruição ou rompimento de obstáculo restará caracterizado um furto qualificado (art. $155^{5} \S 4^{\circ} \mathrm{I}$ do $\mathrm{CPB}$ ).

\footnotetext{
${ }^{4}$ Art. 157 - Subtrair coisa móvel alheia, para si ou para outrem, mediante grave ameaça ou violência a pessoa, ou depois de havê-la, por qualquer meio, reduzido à impossibilidade de resistência:

Pena - reclusão, de 4 (quatro) a 10 (dez) anos, e multa.

${ }^{5}$ Art. 155 - Subtrair, para si ou para outrem, coisa alheia móvel:

Pena - reclusão, de 1 (um) a 4 (quatro) anos, e multa.

$\S 4^{\circ}$ - A pena é de reclusão de 2 (dois) a 8 (oito) anos, e multa, se o crime é cometido:

I - com destruição ou rompimento de obstáculo à subtração da coisa;
} 


\section{REVISTA ELETRÔNICA DA FACULDADE DE DIREITO DE FRANCA \\ www.revista.direitofranca.br \\ v. 6, n.1, dez/2012, ISSN: 1983-4225}

Por fim, se, ainda na mesma ação, não houver emprego de violência, tampouco a coisa seja subtraída com destruição ou rompimento de obstáculo; abuso de confiança, mediante fraude ou escalada; com emprego de chave falsa ou mediante concurso de pessoas, o furto se qualificará simplesmente pela destreza do sujeito ativo, isto é, pelo fato dele subtrair a coisa usada pela vítima, sem que ela perceba(art. $155 \S 4^{\circ}$ II do CPB). De sorte a que é quase impossível praticar um crime lesando o patrimônio da classe dominante sem uma circunstância que o qualifique, aumente ou majore sua pena.

Tais leis, por óbvio, tornam marginalizados todos que não compactuam dos valores selecionados para proteção, portanto, é imperioso concluir que os marginalizados serão mais vulneráveis a infringir à norma posta, uma vez que não raro, sua educação familiar não comporta ditos valores, e que inúmeras normas são até contra suas necessidades. De tal modo que a utilização do Estado e do direito pela classe dominante, cria a figura do delinquente ${ }^{6}$.

Nesse sentido, não é demais constatar que a seleção dos bens protegidos, dos comportamentos lesivos e o "caráter fragmentário" do direito penal perde a ingênua justificação baseada sobre a natureza das coisas ou sobre a idoneidade técnica de certas matérias, e não de outras, para ser objeto de controle penal, vez que esse processo de criminalização se direciona aos comportamentos típicos dos indivíduos das classes subalternas (BARATTA, 1999, p. 165).

Para um melhor entendimento dos valores da classe dominante na sociedade globalizada, que serão colocados na criminalização primária (norma abstrata), é necessário nos reportarmos à atual doutrina econômica neoliberal, uma vez que essa doutrina tem como objetivo a expansão do mercado consumidor, e, consequentemente, transforma os cidadãos em consumidores, excluindo todos que não ostentarem esta condição.

Essa sociedade de consumo tende a criar em países como o Brasil um grupo que "não responde à dialética explorador/explorado, senão a uma relação de excluído e incluído. $\mathrm{O}$ explorado contava, era tido em conta e estava dentro do sistema; o excluído não conta, está sobrando, é um descartável que não serve, só atrapalha” (ZAFFARONI, 1997, p. 35-36).

II - com Abuso de confiança, ou mediante fraude, escalada ou destreza;

III - com emprego de chave falsa;

IV - mediante concurso de duas ou mais pessoas.

${ }^{6}$ Esse fenômeno não é recente no Brasil, basta lembrarmos a criminalizaçãotrazida pelo código penal brasileiro de 1890 da vadiagem (art. 399) e da greve (art. 206), motivada pelas eventuais consequências da abolição da escravatura (WERMUTH, 2011, p. 381). 


\section{REVISTA ELETRÔNICA DA FACULDADE DE DIREITO DE FRANCA \\ www.revista.direitofranca.br \\ v. 6, n.1, dez/2012, ISSN: 1983-4225}

Em sendo assim todos aqueles que não puderem consumir segundo as leis do mercado, serão marginalizados e deverão ser contidos, a fim de não atrapalhar o "poder" de consumo dos demais membros privilegiados da sociedade. Afinal, os "não consumidores" serão impulsionados para tal comportamento, ora, quem não deseja andar segundo as leis do mercado?

É o que bem observa Elbert (2000, p. 68-69),

Existe um modelo de classe média alta, com várias casas e carros, em que a fartura é a palavra de ordem, ao luxo e ao desperdiço, se somam a esnobação e a opulência, se contrapõe uma classe de miseráveis em que o mínimo para sobrevivência não existe, imperando, sim, a fome, a doença e o desespero. Como conceber que em tal sociedade possa haver disciplina social, segundo a qual as massas famintas adotem bons modos e não molestem aqueles cujos modos de vida se traduzem, via de regra, em excessos.

É notória a extrema valorização do patrimônio na sociedade atual, porém, lembramos que o Brasil nasceu desigual, sendo um dos nossos maiores problemas sociais a falta de distribuição de renda, máxime porque nunca na história do país tivemos políticas públicas sérias que incluíssem aqueles historicamente excluídos.

Desta forma, a maioria da população brasileira não possui imensos patrimônios, sendo, portanto, por um processo violento de segregação (relação de consumo), empurrada para as favelas ${ }^{7}$, tornando-se um grupo marginalizado passivo de um controle social localizado, visto que "o empreendimento neoliberal precisa de um poder punitivo onipresente e capilarizado, para o controle penal dos contingentes humanos que ele mesmo marginaliza" (BATISTA, 2002, p. 272).

\section{CRIMINALIZAÇÃO SECUNDÁRIA: ATUAÇÃO DIFERENCIADA DA POLÍCIA SOBRE AS CLASSES SUBALTERNAS}

A criminalização secundária acentua ainda mais o caráter seletivo do direito penal, conforme dito alhures, a criminalização primária exsurge na seleção dos bens jurídicos protegidos pelo direito penal (legislador), já a criminalização secundária advém da aplicação

\footnotetext{
${ }^{7}$ A estética das grandes cidades brasileiras demostra que enquanto os bairros centrais são valorizados e se transformam em objeto de investimentos urbanísticos, as áreas marginais são caracterizadas pela crescente degradação, transformando-se em área de "risco" responsáveis por gerar um crescente e difuso sentimento de medo. (WERMUTH, 2011, p. 388).
} 


\title{
REVISTA ELETRÔNICA DA FACULDADE DE DIREITO DE FRANCA \\ www.revista.direitofranca.br \\ v. 6, n.1, dez/2012, ISSN: 1983-4225
}

seletiva e diferenciada da norma abstrata pelos órgãos formais do sistema penal (Polícia, Juízes, Ministério Público etc.).

Dessa maneira, temos dois tipos de criminalização para aqueles indesejáveis à sociedade neoliberal, a primeira se dá na seleção dos bens jurídicos, enquanto a segunda, na aplicação da norma que já nasceu tendenciosa. Assim, pode-se concluir que, "o Direito Penal, fundado nos preceitos construídos pela dogmática, não atinge a todos igualmente, pelo simples fato da existência da seletividade no momento da criminalização primária e secundária"(GUIMARÃES, 2010, p. 35).

Por óbvio o sistema penal está obrigado sempre a selecionar, para comprovar isso basta nos reportamos à grande cifra oculta, que por sua vez é explicada pela fragilidade da capacidade operativa das agências de criminalização secundária. Assim, por ser uma atividade seletiva, não reconhece o princípio da igualdade, o que implica certo grau de violência, de arbitrariedade e, portanto, de corrupção (ZAFFARONI, 2000, p. 47).

Dentre esses órgãos formais responsáveis pela aplicação do direito, encontra-se a polícia, cuja função, de forma sucinta é a preservação da ordem pública e a apuração de infrações penais.

Frise-se que, a polícia é determinante na seleção daqueles sobre quem ocorrerá a subsunção das normas penais - "gerais" e abstratas -, vez que, em regra, o sistema penal obtém movimento com o exercício da atividade policial, e por conseguinte, é a primeira instituição de controle social formal a ter contato com o suspeito. Ademais, "na realidade, tem maior poder seletivo dentro do sistema penal a polícia do que o legislador, pois aquela opera diretamente sobre o processo de "filtração" do sistema"(ZAFFARONI E PIERANGELI, 2004, p. 70-71).

Sobre o assunto Sabadell (2008, p. 231) diz que,

\begin{abstract}
A polícia participa de forma decisiva na aplicação do direito, enquanto corpo organizado que se encarrega do controle social nos seus aspectos mais "fortes" (repressivos). Ela efetua a primeira filtragem dos futuros "clientes" do sistema (seleção secundária). De sua atuação depende o modo da aplicação e o grau de eficácia do direito, sobretudo na área penal.
\end{abstract}

É exatamente essa atuação seletiva, diferenciada, violenta e acima de tudo impregnada de preconceitos (visando estereótipos) da polícia, condicionada ao grupo sobre o qual recai a sua ação o ponto nodal do presente artigo. Noutro giro, a forma que a polícia atua em 


\section{REVISTA ELETRÔNICA DA FACULDADE DE DIREITO DE FRANCA \\ www.revista.direitofranca.br \\ v. 6, n.1, dez/2012, ISSN: 1983-4225}

membros das classes privilegiadas, não é, nem de longe, comparada com a atuação em face, como é de fácil percepção, das classes subalternas. Assim sendo, exsurge um caráter pessoal na atividade policial, de tal sorte que, aparece uma atuação por cara, visando o autor e não a conduta.

Nesse diapasão, é cediço que não raro a polícia invade bairros periféricos com uma postura violenta, o que além de extrapolar suas funções institucionais trazidas pela nossa atual Constituição Federal, causa uma imensa insegurança, na medida em que pelo uso arbitrário da força atuam, em regra, de forma autoritária.

Essa atuação covarde, somada com a atuação do resto da cadeia (juízes e promotores), além de perigosa, uma vez que a polícia é detentora de um poder legitimado, transporta efeitos absurdos ao sistema penal, consubstanciados em agressões, mortes, ameaças e um forte encarceramento das populações subalternas, tendo em vista que devido à seleção pela polícia, sobre elas ocorrerá à subsunção da norma penal. Principalmente porque pela falta de um controle efetivo a políciatem grande oportunidade para a prática das ações supracitadas, o que está totalmente em desacordo com a nossa Constituição cidadã (GUIMARÃES, 2010, P. 136).

Transformando a exceção em regra os agentes policiais, não raro, atuam de forma letal sobre supostos criminosos, fundamentados na argumentação de que o agente passivo apresentou "resistência", ocorre que, deve-se eliminar a resistência e não quem resiste. Tanto é assim que na declaração dos Princípios Básicos sobre a Utilização da Força e de Armas de Fogo pelos funcionários responsáveis pela aplicação da lei, adotada pelo oitavo congresso das nações unidas para a prevenção dos crimes e tratamento dos delinquentes, o uso da força e o emprego de armas de fogo só é legitimo em ultima ratio(Greco, 2011, p. 34).

É o que leciona Oliveira (2011, p. 564),

As prisões, seja em flagrante, seja por mandado judicial, serão efetuadas sem o emprego de força, salvo a indispensável para vencer eventual resistência ou eventual tentativa de fuga (art. 284 CPPB), (...). Nesse campo, o emprego de armas exclusivamente para evitar a fuga não pode ser aceito como meio indispensável para vencer a resistência, podendo constituir, isso sim, dependendo do caso concreto, crime doloso contra a vida.

Ademais, o exercício da atividade policial de forma letal, além de incompatível com o Estado Democrático de Direito (vez que feri princípios básicos), traz consequências drásticas 


\section{REVISTA ELETRÔNICA DA FACULDADE DE DIREITO DE FRANCA \\ www.revista.direitofranca.br \\ v. 6, n.1, dez/2012, ISSN: 1983-4225}

à sociedade civil, pois é formado pela polícia um "tribunal de rua", que cujas regras não permitem, como preceitua a nossa Constituição Federal, um devido processo legal ao cidadão.

Sobre o sistema penal subterrâneoZaffaroni (2003, p. 52-53; 69-70) diz que

O sistema penal subterrâneo é exercido pelas agências executivas de controle portanto, pertencentes ao Estado- à margem da lei e de maneira violenta e arbitrária, contanto com a participação ativa e passiva em maior ou menos grau, dos demais operadores que compõem o sistema penal (...).O sistema penal subterrâneo institucionaliza pena de morte, desaparecimentos, torturas, sequestros, exploração do jogo, da prostituição, entre outros delitos.

Além do que, Bayley (2006, p. 234), percebe que "a polícia reproduz, sem perceber, um esquema vindo diretamente do século XIX: a criminalização das camadas sociais mais desfavorecidas e a confusão entre "classes laboriosas" e "classes perigosas"“.

De mais a mais, frise-se que atos deste jaez são típicos dos Estados absolutistas, afinal, eram estes que não estavam sobre os ditames da "impessoalidade" da lei.

Sobre o tratamento condicionado a classe a qual se pertença, Foucault (2003, p. 35) destaca que,

É segundo a classe social à qual se pertença, segundo as possibilidades de fortuna, segundo as posições sociais que se obtêm a justiça. A justiça não lhe é atribuída do mesmo modo. Essa desigualdade diante da justiça que, no século XVII, já era muito vivamente experimentada e contra a qual reagiram Beccaria e Bertin e os grandes códigos napoleônicos, essa desigualdade restaurou-se, se é que ela em algum momento foi suspensa. Ela se restaurou e, atualmente, as pessoas sofrem dela de modo violento. Tem-se o sentimento quase cotidiano dessa desigualdade diante da justiça e diante da polícia.

Uma polícia violenta, autoritária e seletiva ao oposto do que se espera, causa um desfavor à sociedade, na medida em que não traz um sentimento de segurança, mas ao contrário, de medo, e como consequência insegurança,não é por acaso que a maioria da população tem uma opinião negativa em relação à polícia. “Assim, por exemplo, em pesquisa de opinião feita em todo o Brasil em 2002, 59\% dos entrevistados declararam que tinham “mais medo do que confiança” na polícia” (SABADELL, 2008, p. 234).

Temos assim uma inversão dos polos, ora, fatos desta natureza são incoerentes, é dizer, a sociedade está dando um poder legitimado a policiais que na verdade são criminosos.

Nesse sentido Amaral preleciona (2003, on-line) que,

O policial, tem o dever de exercer a autoridade concedida para tal fim, sob pena de estar prevaricando, mas não pode extrapolar, sob pena de estar praticando abuso de 


\title{
REVISTA ELETRÔNICA DA FACULDADE DE DIREITO DE FRANCA \\ www.revista.direitofranca.br \\ v. 6, n.1, dez/2012, ISSN: 1983-4225
}

autoridade. Prevaricação e abuso (ou desvio) de autoridade são crimes. Com efeito, a atividade daquele que lida com a segurança pública é deveras importante, mas exigese sempre o bom senso e o equilíbrio nas ações, até porque estas se refletem como um todo na sociedade.

Ademais, as classes subalternas, donde geralmente são os sujeitos passivos da abordagem policial, são submetidas à revista debaixo de frases carregadas de arrogância e prepotência, com tom pouco amistoso, tais como "encosta, encosta, ninguém corre se não leva tiro". O que de plano demonstra um abuso na atuação da polícia, cuja função é a apreensão e a condução à delegacia de eventuais suspeitos, ou seja, toda a sua atividade, seja nos bairros periféricos, seja nos bairros nobres, deve ser direcionada e proporcional a tal fim, sob pena de atuarem com abuso de autoridade.

Soares (2000, p.170),

\begin{abstract}
Nesse contexto torna-se claro que os problemas decorrentes da desigualdade social são tratados de forma violenta e inadequada. Isto é indicado por pesquisas representativas e participantes e também por que envolveu mais de 2.000 pessoas no Distrito Federal, 14\% declarou ter sido vítima de violência policial e 51\% disse que conhecia alguém que foi vitima deste tipo de violência ou tinha ouvido relatos a este respeito.
\end{abstract}

Corroborando o que é defendido nesse trabalho, se percebe aindaque a atuação hostil da polícia recai, em regra, sobre aqueles que trazem consigo o perfil do criminoso (atuação por cara/pessoal), perfil que como dito alhures, devido à extrema valorização do patrimônio, é quase sempre inerente àqueles que não andam de acordo com, e, ou não sustentam os padrões da sociedade neoliberal, sendo em geral negros, cujas vestimentas são de marcas que não têm expressividade no cenário nacional ou internacional.

Nas palavras de Wermuth (2011, p. 388),

Com as reformas neoliberais que se verificam na sociedade brasileira nas últimas décadas, essa seletividade assume proporções incomensuráveis, visto que, a partir delas, somam-se à população historicamente perseguida pelo sistema punitivo o espólio da escravidão os contingentes populacionais que são banidos do mercado de trabalho e da sociedade de consumo porque não dispõe de meios de participação efetiva. Ou seja, são consumidores falhos para os quais só resta a segregação, tanto pela via da marginalização social especial, quanto por meio do encarceramento em massa e da eliminação pura e simples a partir da intervenção violenta do sistema punitivo.

Outrossim, essa prepotência e arbítrio na atividade policial, percebidas nas batidas (operações da polícia que são feitas em lugares suspeitos), trazem a tona o autoritarismo desta 


\title{
REVISTA ELETRÔNICA DA FACULDADE DE DIREITO DE FRANCA \\ www.revista.direitofranca.br \\ v. 6, n.1, dez/2012, ISSN: 1983-4225
}

instituição, uma vez que partem do dogma de que aqueles cidadãos são, além de suspeitos, criminosos, e por isso suas ações são cercadas de ordens e afirmações desrespeitosas, além de agirem com a finalidade de eliminar o estigmatizado inimigo.

Amaral (2003, on-line), traça as principais diferenças do militar para o profissional da guerra,

\begin{abstract}
A formação do militar, que é essencialmente profissional da guerra, não deve ser confundida com a do policial, mesmo porque o mais cruel dos bandidos não é o inimigo mortal a ser eliminado (senão a ser preso) como é fato normal e decisivo nas guerras. A essência da guerra é a eliminação do inimigo, a essência da missão policial é preservar a ordem pública e prender o criminoso, nada mais que isso (...). Essa confusão na formação e na rotina operacional do policial explicam muitas de nossas crises no sistema de segurança pública brasileiro.
\end{abstract}

Nessa senda, sobre o sujeito passivo da atuação policial recaem palavras do tipo "ê malandro perdeu, passa, passa! É melhor me entregar do que eu procurar"; o que dar a entender que não é uma revista sobre um suspeito, mas, uma certeza de que o destinatário da ação encontra-se com objeto-valor que caracterize crime ou seus instrumentos."Os grupos sociais mais fracos não somente são considerados, com maior facilidade, como suspeitos e culpados; são também as principais vitimas da violência policial, que assume indevidamente o papel do justiceiro" (SABADELL, 2008, p. 233).

Dito de outro modo, tais comportamentos têm o condão de trazer intimidação, seja através de palavras ameaçadoras (violência moral), seja através de agressão (violência física), ou até mesmo pela posse e esbanjamento de armas pesadas ou pelo número de policiais na atuação, vez que "no Brasil, a polícia, como a prisão, tem papel de intimidação absoluta, através do terror, daqueles segmentos sociais que ameaçam os privilégios das elites." Dornelles (1997, p. 103-120).

Desta maneira por serem os bairros periféricos mais vigiados e controlados pela polícia, são, em geral, indivíduos pertencentes a essas comunidades que sentam no banco dos réus, tal fato pode ser facilmente observado quando se analisa a clientela do sistema prisional no Brasil, o que comprova o poder de seleção da polícia.

Logo, não se pode crer que se destine ao acaso o fato de o papel de criminoso ser, quase invariavelmente, atribuído às pessoas de níveis sociais mais baixos, tendo-se em conta que são essas pessoas que devem ser diuturnamente vigiadas, reprimidas e mantidas isoladas 


\title{
REVISTA ELETRÔNICA DA FACULDADE DE DIREITO DE FRANCA \\ www.revista.direitofranca.br \\ v. 6, n.1, dez/2012, ISSN: 1983-4225
}

para que o poder possa perpetuar-se sem maiores distúrbios, sem crises, sem confrontos para com o seu discurso legitimador (GUIMARÃES, 2010, p. 195).

Essas condutas a margem da legalidade são uma crassa violação ao princípio da dignidade da pessoa humana, norteador de todo nosso sistema jurídico, visto que é fundamento para os princípios que caracterizam um Estado Democrático de Direito.

Em síntese Greco (2011, p. 10),

O princípio da dignidade da pessoa humana serve como princípio reitor de muitos outros, tal como ocorre com o princípio da individualização da pena, da responsabilidade pessoal, da culpabilidade, da proporcionalidade etc., que nele buscam seu fundamento de validade.

Por fim, é mister ressaltar que os direitos humanos não estão condicionados a um dever para com o Estado, mas à condição de ser humano. De sorte a que, por mais que alguém cometa um ilícito penal, isso não abre a possibilidade de uma atuação violenta por parte do Estado, tendo em vista que uma polícia eficiente não é sinônimo de polícia com atitudes agressivas.

Nesse sentido, claro é Amaral (2003, on-line), quando diz que,

\begin{abstract}
Os direitos humanos não são antíteses de polícia eficiente, senão de polícia barbara, violenta, não profissional.(...). Se um policial é capaz de transigir nos seus princípios de civilidade quando no contato com o cidadão - pode-se imaginar quando em contato com os criminosos - abona a violência que profissionalmente devia eliminar, contamina-se com o que nega, rebaixando-se, assim, à igualdade de procedimentos com aqueles a quem combate (os bandidos).
\end{abstract}

\section{CONSIDERAÇÕES FINAIS}

É mister que se estabeleça a diferença entre o discurso dogmático ensinado nas universidades e a realidade, principalmente no âmbito punitivo, vez que, no Brasil o discurso de defesa social e de manutenção da paz, não passam de ideologias para a perpetuação da desigualdade social, o que atenta, de plano, ao Estado Democrático de Direito.

Não temos uma sociedade com interesses uniformes, mas ao contrário, uma diversidade de interesses, todavia, a classe dominante através da utilização do Estado e do direito, estabelece seus valores, por meio de ideologias, como se fossem anseios de todos, e por consequência cria a figura do delinquente, movimentando a polícia para um controle localizado e violento destes marginalizados a fim de evitar incômodo em seus privilégios. 


\section{REVISTA ELETRÔNICA DA FACULDADE DE DIREITO DE FRANCA \\ www.revista.direitofranca.br \\ v. 6, n.1, dez/2012, ISSN: 1983-4225}

O Brasil tem características autoritárias, o que tornar nossas instituições de controle ao corpo social mais violentas e rigorosas, é o exemplo da polícia, instituição de controle social que vigora no meio urbano, cuja função latente é a repressão daqueles que desafiarem as ordens sociais estabelecidas no meio social.

Não restam dúvidas de que os bairros periféricos são mais vigiados e controlados pela polícia, e desta maneira são, em geral, indivíduos pertencentes a essas comunidades que sentam no banco dos réus, máxime pelo poder de seleção da polícia, que se direciona aos cidadãos que não ostentam os padrões da sociedade neoliberal.

Por fim, não se tem justificativas para esse comportamento seletivo, covarde e violento, vez que o Brasil se declara como um Estado Democrático de Direito, e em Estados desse jaez não se admite privilégios, o que traz a necessidade de uma democratização das nossas instituições formais de controle social, tendo em vista que ao se comportarem desta maneira os agentes destes órgãos trazem à tona sua falta de compromisso com a justiça social.

\section{REFERÊNCIAS BIBLIOGRÁFICAS}

ALBRECHT, Peter-alexis. Criminologia: uma fundamentação para o direito penal. Trad.Juarez Cirino dos Santos e HelenaSchiesse Cardoso. Curitiba: ICPC/Lumen Juris, 2010.

AMARAL, Luiz Otavio O. Direitos humanos e violência policial. Uma polícia menos letal: o profissionalismo policial. Jus Navigandi, Teresina, ano 8, n. 63, 1 mar. 2003. Disponível em: <http://jus.uol.com.br/revista/texto/3794>. Acesso em: 28 maio 2011.

BARATTA, Alessandro. Criminologia crítica e crítica do direito penal: Introdução à sociologia do direito penal; tradução Juarez Cirino dos Santos. 3. ed. Rio de Janeiro: Revan, 2002.

BATISTA, Nilo. "Mídia e sistema penal no capitalismo tardio", In: discursos sediciosos. Crime, direito e sociedade. Rio de Janeiro, ano 7, n. 12, p. 271-290, 2.semestre de 2002.

BAYLEY, David. Padrões de policiamento: uma análise comparativa internacional. São Paulo: Edusp, 2006 (Coleção Polícia e Sociedade; n.1).p. 200-250.

BITTAR, Eduardo Carlos Bianca; ALMEIDA, Guilherme Assis. Curso de filosofia do direito. 7. ed. São Paulo: Atlas, 2009.

BITENCOURT, Cezar Roberto. Lições de direito penal:Parte geral. Porto Alegre: Livraria do Advogado, 2005, p. 15-50.

DORNELLES, João Ricardo Wanderley. Violência urbana, direitos da cidadania e políticas públicas de segurança no contexto de consolidação das instituições 


\section{REVISTA ELETRÔNICA DA FACULDADE DE DIREITO DE FRANCA \\ www.revista.direitofranca.br \\ v. 6, n.1, dez/2012, ISSN: 1983-4225}

democráticas e das reformas econômicas neoliberais. In: discursos sediciosos. Crime, direito e sociedade. Rio de Janeiro, ano 2, n. 4, p. 103-120, 2.semestre de 1997.

ELBERT, Carlos Alberto. Criminologia latino-americana. Teorias e Propostas sobre o controle social no terceiro milênio. São Paulo: LTr, 2000.

FOUCAULT, Michel. Estratégia, poder-saber. Tradução de Vera Lúcia de Avellar Ribeiro. Rio de Janeiro: Forense Universitária, 2003.

FREIRE, Paulo. Pedagogia do oprimido. 12 ed. Rio de Janeiro: Paz e Terra, 1983.

.Pedagogia da autonomia: Saberes necessários à prática educativa.

São Paulo: Paz e terra, 1996, (coleção leituras), p. 12-33.

FREITAS, Wagner Cinelli de Paula. Espaço urbano e criminalidade: Lições da escola de Chicago. São Paulo: IBCCRIM, 2002.

GRECO, Rogério.Direito penal do equilíbrio: uma visão minimalista do Direito Penal. 5. ed.Rio de Janeiro: Impetus, 2010.

Atividade policial: aspectos penais, processuais penais, administrativos e constitucionais.3.ed. Rio de Janeiro: Impetus, 2011.

GUIMARÃES, Claudio Alberto Gabriel. Constituição, ministério público e direito penal: A defesa do Estado Democrático no âmbito punitivo. Rio de Janeiro: Revan, 2010.

HOLANDA, Sérgio Buarque de. Raízes do Brasil.26.ed. São Paulo: Companhia das Letras, 1995.

NUCCI, Guilherme de Souza. Princípios constitucionais e processuais penais. São Paulo: Revista dos Tribunais, 2010.

OLIVEIRA, Eugênio Pacelli de. Curso de processo penal. 15. ed. Rio de Janeiro: Lumes Juris, 2011.

SABADELL, Ana Lucia. Manual de sociologia jurídica: Introdução a uma leitura externa do direito.4.ed. São Paulo: Revista dos Tribunais, 2008.

SAVIANI, Dermeval. Escola e democracia: Teorias da educação, curvatura da vara, onze teses sobre educação e política. São Paulo: Cortez, 1977, (Coleção polêmicas do nosso tempo ;v. 5), p. 3-18.

SILVA, José Afonso da.Curso de direito constitucional positivo.20.ed., São Paulo: Malheiros, 2002.

SOARES, Gláucio Ary Dillon. Quem tem medo da PM? A confiança na polícia militar do Distrito Federal e suas relações com variáveis estruturais, demográficas e a experiência com a violência. Revista Brasileira de CiênciasCriminais, n. 32, 200, p. 269-277.

WACQUANT, Loïc. Os condenados da cidade: estudos sobre a marginalidade avançada[tradução de João Roberto Martins Filho, et al]. 2. ed. Rio de Janeiro: Revan, 2005.

WERMUTH, Maiquel Ângelo Dezordi.Uma análise histórica da imposição do medo do direitopenal aos setores subalternos da população brasileira. Revista Brasileira de Ciências Criminais. Vol.90. p. 373-399. São Paulo: Ed. RT, maio-junho, 2011. 


\section{REVISTA ELETRÔNICA DA FACULDADE DE DIREITO DE FRANCA \\ www.revista.direitofranca.br \\ v. 6, n.1, dez/2012, ISSN: 1983-4225}

ZAFFARONI, Eugenio Rául. Direito Penal brasileiro: Teoria Geral do Direito Penal. Rio de Janeiro: Revan, 2003.

; PIERANGELI, José Henrique. Manual de direito penal brasileiro: parte geral. 5. ed. São Paulo: Revista dos Tribunais, 2004. 